\title{
How to decrease the negative effects of medium intensity disturbances on arthropod communities
}

\author{
G. Györffy and L. Körmöczi
}

Györffy, G. and Körmöczi, L. 2001. How to decrease the negative effects of medium intensity disturbances on arthropod communities. - Web Ecol. 2: 14-21.

\begin{abstract}
One of the major goals in nature conservation practice is to optimise the timing or the method of treatments or both. We studied the response of the Auchenorrhyncha (Insecta: Homoptera) assemblage to annual mowing in three different locations along an elevation gradient of a mesic grassland. Several weeks after mowing, the total number of imagoes and larvae decreased considerably, and the relative abundance differences between populations at different elevations also decreased, reflecting the density dependent effect of this treatment. The rate of changes in species composition was greatest in the microhabitats with more comfortable microclimates, in the opposite direction of the alteration of abundance, perhaps interfering with the migration. By the next spring the fauna of the wettest habitat proved to be the most sensitive to mowing and the most different from the others. The overall similarity of the insect communities increased, i.e. the community-level biodiversity decreased due to homogenising effect of mowing. In a heteromorphous habitat, the variability of spatio-temporal dynamics of the populations makes it impossible to find either single optimal time or optimal rotation plan for treatment based on the habitat types. For this reason, we suggest mowing in stripes parallel to the elevation gradient, which would mean synchronous treatment of each microhabitat instead of randomly chosen patches, where the execution is problematic. It is easier to keep the ratio of treated to untreated areas at $50 \%$. Stripes should be narrow enough to provide the possibility of migration to favourable habitat patches, and should not hinder mechanical mowing. Suggested width of stripes is $10-15 \mathrm{~m}$ for Auchenorrhyncha.
\end{abstract}

G. Györffy (gyorffy@bio.u-szeged.hu) and L. Körmöczi, Dept of Ecology, Univ. of Szeged, P.O. Box 51, H-6701 Szeged, Hungary.

Different kinds of treatments (e.g. mowing) for nature conservation are often applied to prevent the undesirable successional changes (e.g. forestation of a grassland) of certain communities. The anthropogenic plagioclimax (Curry 1994) of grasslands has been maintained by human activities (grazing, cutting, or burning). Conservationists have generally regarded the scientific importance of many grasslands as botanical (Morris 1967, Collins et al. 1998). Unfortunately, nature conservation is dominated by concepts that originated from agriculture or other unsuitable sources (Morris and Plant 1983), instead of those which consider the ecological demands of many different plant and animal species (Morris 1982). Management which favours one species may damage others. Appropriate timing of treatment is an important consideration (Morris 1973, Smith et al. 1996). The treatment period used in this paper was designed to take into account the phenology of vegetation, the flowering of certain protected plant species, or the economical-technical considerations. Mowing is an appropriate kind of treatment because its timing and frequency are not as constrained as those of grazing (Morris and Plant 1983). 
In nature reserves, it is necessary to optimise the timing of treatments so that the members of certain ecological communities suffer the smallest negative effect possible, while still fulfilling the original goals. Our aims were to determine the effects of annual mowing on insect communities and, according to the results, to give recommendations for the optimal method of treatment.

\section{Materials and methods}

\section{Investigated area}

Investigations were carried out in the "Ásotthalmi Láprét" nature reserve, located in the south-eastern corner $\left(19^{\circ} 51^{\prime} \mathrm{E}, 46^{\circ} 12^{\prime} \mathrm{N}\right)$ of the sandy table-land of DanubeTisza Interfluve, Hungary. The ninety-five hectare area is a spatially heteromorphous grassland habitat. The surface combines small sand hills and wind-furrows with a characteristic elevation difference of 4-5 m.

Five main plant communities developed in the area: Astragalo-Festucetum rupicolae is characteristic on the sand hills, Astragalo-Festucetum rupicolae Chrysopogon type in the deeper terrain, Succiso-Molinietum coeruleae around the sand hills, Salicetum rosmarinifoliae in the windfurrows, and Scirpo-Phragmitetum in the deepest parts. The ratio of native plants which suffer disturbance is 24.4\%, which is rather high (Kószó 1989). This is because of the annual mowing of the area for the past thirty years around mid-July, which was to prevent the spreading of Phragmites australis.

The reference animal group was the Auchenorrhyncha (Insecta: Homoptera) assemblage. More than 100 Auchenorrhyncha species inhabit this area (Györffy and Abdai 1996), and this number is about twice as high as in either sand grasslands or in wet meadows, in general because of the varied conditions of the area, due to the combination of wet and dry biotope types.

\section{Collecting and elaborating methods}

Field samples were taken in 1990, 1997, and 1998. In 1990, from 9 March to 30 November, we placed 115 Barber traps in five columns and 23 rows, and 60 pan traps in three columns and 23 rows. The Barber traps were five metres apart from each other, and the pan traps ten metres apart. The serial numbers of the rows started at the highest terrain. Samples were taken fortnightly.

In 1997 and 1998, $10 \times 10 \mathrm{~m}^{2}$ unmown plots were applied as controls on three different elevations. Previous studies found that the rank correlation between the diversity of the Auchenorrhyncha assemblage in pan trap samples and that of a plant community in a circle of radius $1 \mathrm{~m}$ was the highest (unpubl.). Though some individuals can migrate substantial distances, for the majority $(85 \%)$ of populations in grasslands migration is rather limited as underlined by the fact that the normal flight height is in the range $0-50 \mathrm{~cm}$ above the soil surface (Györffy and Szônyi 1989).

We deciced to place the control plots in the same place as 1990 studies, therefore their size was also limited by the heterogeneity of study area.

Ten pan trap samples and $3 \times 10$ suction trap samples were taken from both the control and mown plots. The sampling times were 2 July, 16 July, 2 September, and 29 September in 1997, and 15 May and 29 May in 1998. Pan traps were working from 2 to 16 July and 8 to 29 September in 1997 , and 15 to 29 May in 1998. The area was mown 8 September, 1997.

The Auchenorrhyncha specimens were picked out under a microscope from the collected material and stored in ethyl alcohol. We computed the average number of individuals and standard error of raw data. Because the sample sizes were small, we used the Mann-Whitney test and the permutation test for two independent samples to test the significance of the difference between the means (Siegel and Castellan 1988). We compared the community compositions using the Renkonen index (Whittaker and Fairbanks 1958). Spatio-temporal dynamics of abundance were analysed using principal component analysis (PCA).

\section{Results}

We analysed the 1990 samples to learn how the chosen insect group is connected to the habitat variability, what its spatio-temporal dynamics are, and whether there is a period where mowing has less of a negative effect.

Larvae mainly develop in the upper terrain in spring and in the lower one in autumn, but imagoes prefer the upper terrain (Fig. 1), perhaps due to their greater mobility. On the basis of total annual individual numbers, the two extremes of elevation maintain more or less the same level of larval development, but the imagoes inhabit mainly the upper and intermediate terrain (Fig. 2). The Pearson correlation coefficient of the spatial distribution of larvae and imagoes is $0.334(\mathrm{p}<0.001)$ from cumulative annual data. The correlation of larval density and elevation is 0.066 (NS), and that of imagoes is $0.783(\mathrm{p}<0.001)$, which refers to the spatial rearrangement of populations.

Figure 3 shows the PCA scatterplot of sample sites on the basis of the temporal dynamics of the abundance of larvae and imagoes, respectively. Sample sites were considered as objects and sampling dates were the attributes. Sites are separated into three groups along the first axis, which is connected to the elevation (Fig. 3a). This effect is more marked in the case of imagoes (Fig. 3b), and that is why we established sample plots at three different terrains for further investigation.

It is worth noticing that in the unmown plots the abundance of larvae shows a strong decrease with time in the 
Fig.1. Abundances of Auchenorrhyncha larvae (a) and imagoes (b) in the Barber trap rows in the different sampling times. Labels 1 to 23 indicate the position of trap rows along the transect: lower values correspond to high relief, higher values are associated with lower relief. The third axis represents the date and time of sampling. The same numbering system is used in Figs 2, 3.
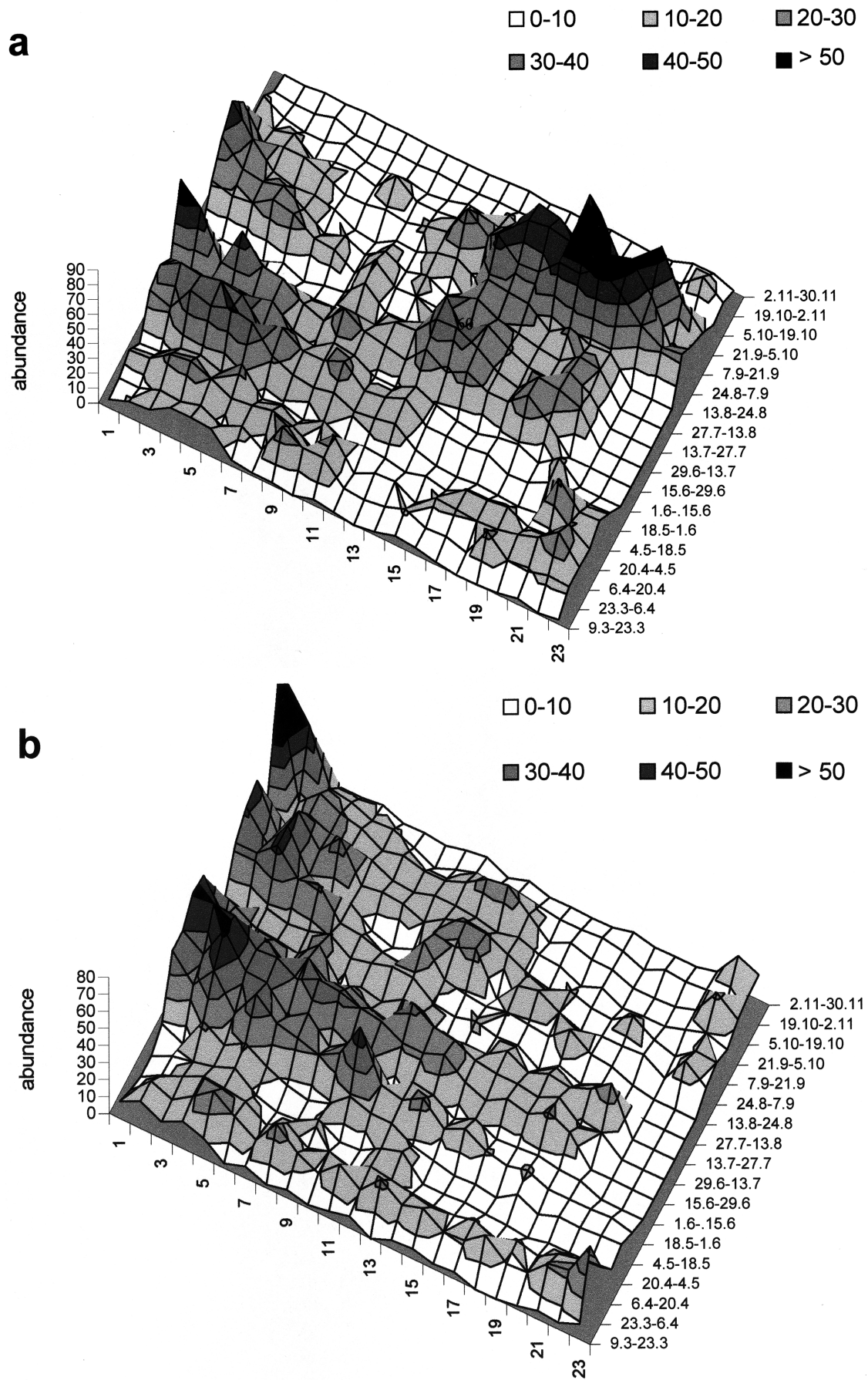

upper terrain and a slight decrease in the intermediate terrain, but in the lower one the abundance had increased again by the beginning of September (Fig. 4). In the intermediate terrain, the abundance was greater in each collecting period than in the lower terrain. Comparing this with the 1990 results (Fig. 1), it is possible that there would not have been such a big break in the shift of larval develop- ment from the upper terrain towards the lower one if the area had not been mown in July, 1990. Mowing in September, 1997 enabled the gradual transition of larval development in the intermediate terrain that year. Also, the abundance change of imagoes shows the transitional character of intermediate terrain (Fig. 4b), but the tendencies are in the opposite direction. 


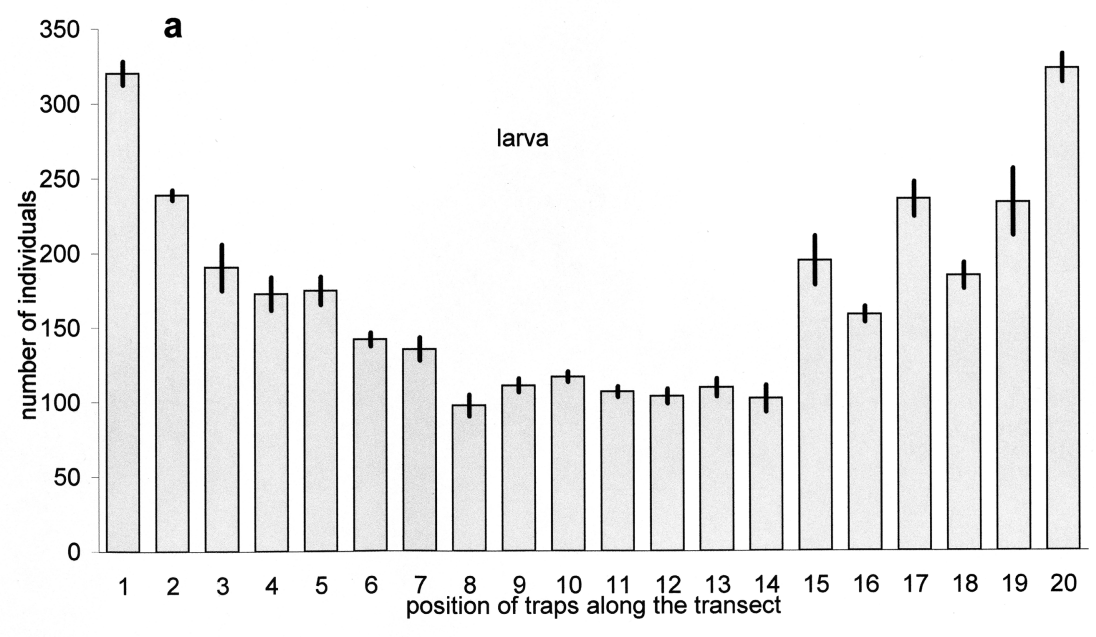

Fig. 2. Sum of average numbers of individuals and standard error of Auchenorrhyncha larvae (a) and imagoes (b) in the pan trap rows. Standardisation is by maximum value.
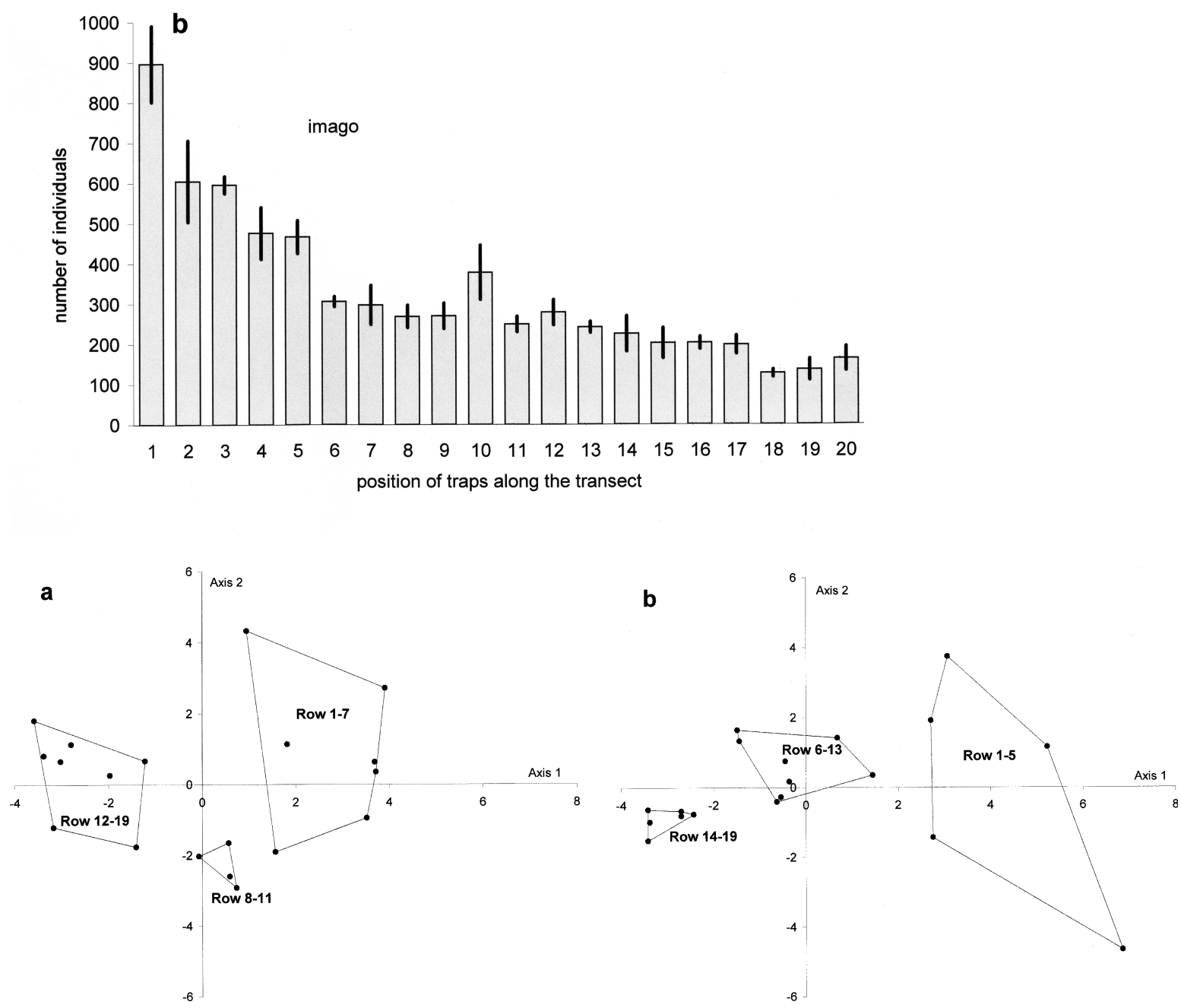

Fig. 3. Principal component analysis (PCA) scattergram of Barber trap rows (sampling sites, as objects) according to the seasonal occurrence of Auchenorrhyncha larvae (a) and imagoes (b). 
Fig. 4. Average number and standard error of Auchenorrhyncha larvae (a) and imagoes (b) in the unmown plots in 1997 , from suction traps.
Fig. 5. Average number and standard error of Auchenorrhyncha larvae (a) and imagoes (b) in the different plots in 29.09. 1997, from suction traps.
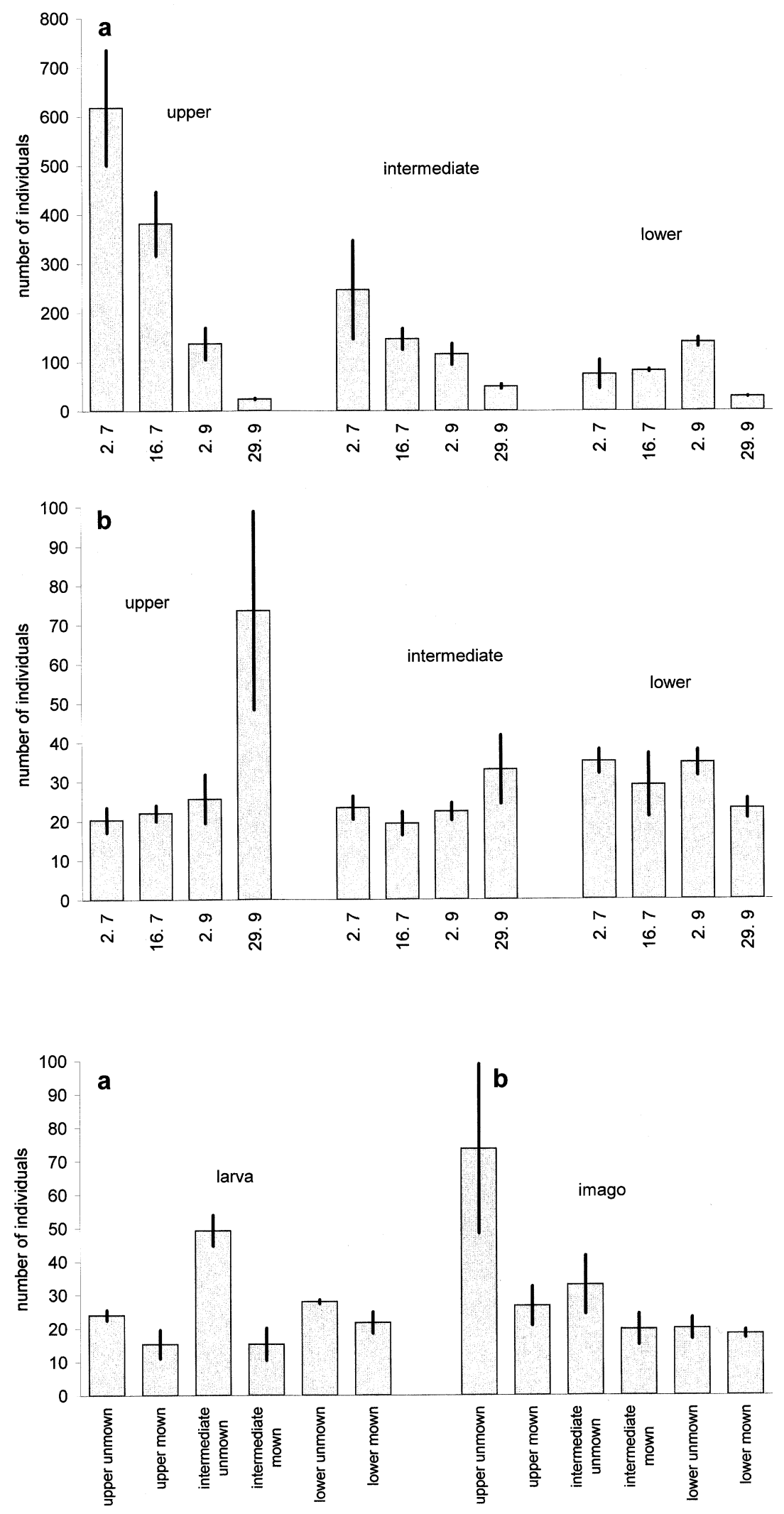
Table 1. Differences between Auchenorrhyncha abundance in mown and unmown plots. N: number of individuals in the two plots, ptest: permutation test, M-W: Mann-Whitney test. Tests are one-tailed, $\alpha$-values are: ${ }^{*}: 0.1,{ }^{* *}: 0.05,{ }^{* * *}: 0.01,{ }^{* * * *}: 0.001$.

\begin{tabular}{|c|c|c|c|c|c|c|c|c|c|}
\hline \multirow[b]{2}{*}{ Sampling date } & \multicolumn{3}{|c|}{ lower terrain } & \multicolumn{3}{|c|}{ intermediate terrain } & \multicolumn{3}{|c|}{ upper terrain } \\
\hline & $\mathrm{N}$ & ptest & M-W & $\mathrm{N}$ & ptest & M-W & $\mathrm{N}$ & ptest & M-W \\
\hline \multicolumn{10}{|c|}{29 Sept 1997 , suction trap } \\
\hline imagoes & 115 & - & - & 55 & - & - & 301 & * & * \\
\hline larvae & 149 & - & - & 741 & $* *$ & $* *$ & 118 & $* *$ & $* *$ \\
\hline \multicolumn{10}{|c|}{ 8-29 Sept 1997, pan traps } \\
\hline imagoes & 538 & - & - & 478 & * & $*$ & 1153 & $* * * *$ & $* * * *$ \\
\hline larvae & 39 & $* * * *$ & $* * * *$ & 39 & $*$ & - & 44 & $* * *$ & $* * *$ \\
\hline \multicolumn{10}{|c|}{15 May 1998 , suction trap } \\
\hline imagoes & 64 & $* *$ & $* *$ & 42 & - & - & 65 & - & - \\
\hline larvae & 898 & $* *$ & $* *$ & 805 & * & * & 783 & - & - \\
\hline \multicolumn{10}{|c|}{29 May 1998 , suction trap } \\
\hline imagoes & 52 & - & - & 55 & - & - & 88 & - & - \\
\hline larvae & 849 & $* *$ & $* *$ & 741 & $* *$ & $* *$ & 1097 & - & - \\
\hline
\end{tabular}

Abundance of both larvae and imagoes decreased after the mowing of each terrain (Fig. 5), though this was not always significant (Table 1). Due to mowing, the total number of imagoes and larvae decreased considerably, which reflects the density dependent effect of this treatment (Fig. 5).

Change of community structure (as a function of relief) is in the opposite direction to that of abundance (Fig. 6). Therefore, the apparent constancy of the number of Auchenorrhyncha individuals on the lower terrain (Fig. 5) is coupled with the greatest changes in species dominance. Migration from the other types of terrain should alter the community structure.

After the winter period, the distribution of larvae became similar to that observed in 1990 by the end of May (Fig. 7). Dominance shifted towards the upper terrain was not observed at the unmown plots. Difference of larval abundance was the largest in the lower terrain (about $50 \%)$, and smallest in the upper terrain $(<5 \%$; Fig. 7 , Table 1).
Mowing homogenises the Auchenorrhyncha communities that assembled by spring (Table 2). The unmown plot of the lower terrain has the most particular community, which is why its rate of change is the greatest.

\section{Discussion}

Mowing decreases the individual number, species number, and diversity of Auchenorrhyncha in general, but there are opposing instances (Andrzejewska 1979, Morris 1967, 1981, 1982, Morris and Plant 1983, Dunwiddie 1991). The degree of negative effect depends on the developmental stage at which the treatment hits the insects (Curry 1994). We can find examples for stronger effects of the treatment both in imago (Morris 1978) and in larval stages (Morris 1982). Considering that imagoes prefer the upper or medium regions of grassland, while larvae reside in the litter zone (Andrzejewska 1965), the effect on imagoes seems stronger. Greater mobility of imagoes enables them

Table 2. Renkonen similarity of Auchenorrhyncha communities on different treatment plots (data are from suction trap, sampling season: May 1998). Values are expressed as percent.

\begin{tabular}{|c|c|c|c|c|c|c|}
\hline & & \multicolumn{2}{|c|}{ lower terrain } & \multicolumn{2}{|c|}{ intermediate terrain } & \multirow{2}{*}{$\begin{array}{l}\text { upper terrain } \\
\text { unmown }\end{array}$} \\
\hline & & unmown & mown & unmown & mown & \\
\hline \multirow[t]{2}{*}{ lower terrain } & unmown & & & & & \\
\hline & mown & 30.3 & & & & \\
\hline \multirow{2}{*}{ intermediate terrain } & unmown & 13.7 & 26.3 & & & \\
\hline & mown & 16.3 & 47.6 & 46.0 & & \\
\hline \multirow[t]{2}{*}{ upper terrain } & unmown & 6.45 & 49.4 & 43.8 & 51.5 & \\
\hline & mown & 6.45 & 48.6 & 61.0 & 57.9 & 65.9 \\
\hline
\end{tabular}




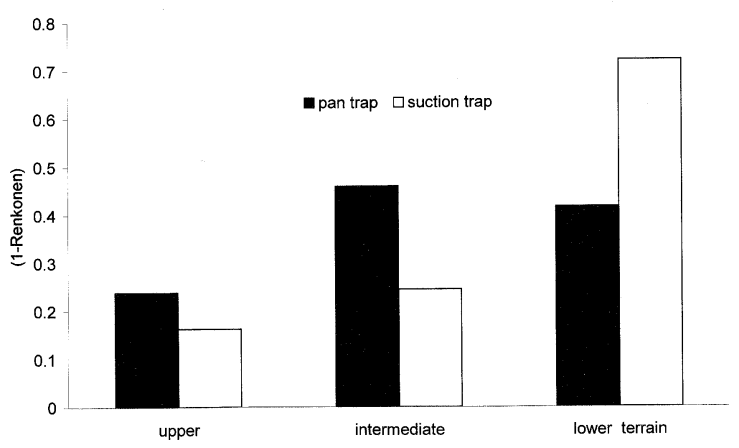

Fig. 6. Rate of changes in community structure (1-Renkonen index of similarity) after mowing in 1997.

to move to more favourable microhabitats, but survival of larvae is threatened mainly in dryer habitats. This should account for the quick recolonisation of the populations after the $75-85 \%$ decrease of imago density caused by mowing (Törmälä 1977, Curry 1987). Similar densities, however, do not refer to similar species composition, as the difference was seen in the case of the community of lower relief. In spite of differences of vegetation, the treatment favours good coloniser species and those with a wide spectrum of host plants (Novotny 1991). This effect should account for the increase in similarity of Auchenorrhyncha communities due to mowing, even in such heteromorphous habitats as the studied area. According to our experiences, in a heteromorphous habitat one can pick out neither a single optimal time for treatment nor an optimal rotation treatment plan based on the habitat types, because of the variability of spatio-temporal dynamics, as was suggested by Morris $(1973,1981)$, Morris and Plant (1983), or Denno (1977).

In different microhabitats, optimal treatment should facilitate the survival of populations at different developmental stages and their chances of migration from treated plots, and should allow the existence of an Auchenorrhyncha species pool for recolonisation. For this reason, we suggest mowing habitats of this kind in stripes parallel to the elevation gradient, which would mean synchronous treatment of each microhabitat. Choosing patches at random each year would be more natural, but the execution of this is problematic. It is easier to keep the ratio of treated to untreated areas at 50\%, and the stripes should be wide enough to provide migration possibilities to favourable habitat patches, and should not hinder mechanical mowing. Suggested width of stripes is $10-15 \mathrm{~m}$ for Auchenorrhyncha. Further investigations are desirable to determine the precise optimisation of stripe width.

Acknowledgements - This project was sponsored by the National Environmental Found (KKA 6573) and the Hungarian Scientific Research Fund (OTKA T 25335). Zsolt Pénzes helped us in carrying out some statistical tests.
Fig. 7. Average number and standard error of Auchenorrhyncha larvae in the different plots in 1998 , from suction traps.

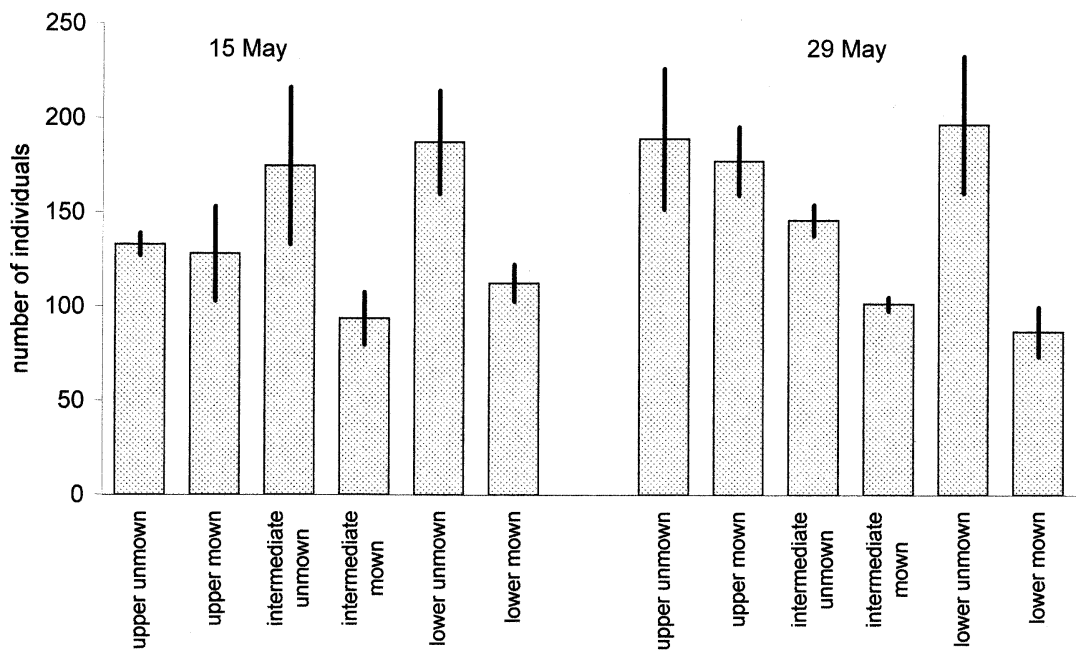




\section{References}

Andrzejewska, L. 1965. Stratification and its dynamics in meadow communities of Auchenorrhyncha (Homoptera). - Ecol. Pol. A 13: 685-715.

Andrzejewska, L. 1979. Herbivorous fauna and its role in the economy of grassland ecosystems. 1. Herbivores in natural and managed meadows. - Polish Ecol. Stud. 5: 5-44.

Collins, S. L. et al. 1998. Modulation of diversity by grazing and mowing in native tallgrass prairie. - Science 280: 745-747.

Curry, J. P. 1987. The invertebrate fauna of grassland and its influence on productivity. II. Factors affecting the abundance and composition of the fauna. - Grass and Forage Sci. 42: $197-212$.

Curry, J. P. 1994. Grassland invertebrates. Ecology, influence on soil fertility and effects on plant growth. - Chapman and Hall.

Denno, R. F. 1977. Comparisons of the assemblages of sap-feeding insects (Homoptera - Hemiptera) inhabiting two structurally different salt marsh grasses in the genus Spartina. Environ. Entomol. 6: 359-372.

Dunwiddie, P. W. 1991. Comparisons of aboveground Arthropods in burned, mowed and untreated sites in sandplain grasslands on Nantucket Island. - Am. Midl. Nat. 125: 206212.

Györffy, G. and Szônyi, G. 1989. Movements of phytophagous insect populations between ungrazed sandy grassland and adjacent areas. - Acta Biol. Szeged. 35: 129-155.

Györffy, G. and Abdai, É. 1996. Auchenorrhyncha assemblages of the "Ásotthalmi Láprét" nature conservation area in Hungary I. - Acta Biol. Szeged. 41: 57-65.

Kószó, M. F. 1989. Ásotthalom védett és fokozottan védett növényei. - Thesis, Budapest.

Morris, M. G. 1967. Differences between the invertebrate faunas of grazed and ungrazed chalk grassland. I. Responses of some phytophagous insects to cessation of grazing. - J. Appl. Ecol. 4: 459-474.
Morris, M. G. 1973. The effects of seasonal grazing on the Heteroptera and Auchenorhyncha (Hemiptera) of chalk grassland. - J. Appl. Ecol. 10: 761-780.

Morris, M. G. 1978. Grassland management and invertebrate animals - a selective review. -Sci. Proc. R. Dubl. Soc. (A) 6: 247-257.

Morris, M. G. 1981. Responses of grassland invertebrates to management by cutting IV. Positive responses of Auchenorhyncha. - J. Appl. Ecol. 18: 763-771.

Morris, M. G. 1982. Some responses of Arthaldeus pascuellus (Hem., Cicadellidae) to changes in an Arrhenatherum grassland. - Z. Angew. Entomol. 94: 351-358.

Morris, M. G. and Plant, R. 1983. Responses of grassland invertebrates to management by cutting $\mathrm{V}$. Changes in Hemiptera following cessation of management. - J. Appl. Ecol. 20: 157-177.

Novotny, V. 1991. Responses of Auchenorrhyncha communities to selected characteristics of littoral and meadow vegetation. - Ekológia (CSFR) 10: 271-282.

Siegel, S. and Castellan, N. J. Jr 1988. Nonparametric statistics for the behavioral sciences. -McGraw-Hill.

Smith, R. S., Pullan, S. and Shiel, R. S. 1996. Seed shed in the making of hay from mesotrophic grassland in a field in northern England: effects of hay cut date, grazing and fertilizer in a split-split-plot experiment. - J. Appl. Ecol. 33: 833841.

Törmälä, T. 1977. Effects of mowing and ploughing on the primary production and flora and fauna of a reserved field in central Finland. - Acta Agricult. Scand. 27: 253-264.

Whittaker, R. H. and Fairbanks, C. W. 1958. A study of plankton copepod communities in the Columbia Basin, southeastern Washington. - Ecology 39: 46-65. 